\title{
“CIDADÃ DE SEGUNDA CLASSE": SUJEITOS FEMININOS E A FRAGMENTAÇÃO IDENTITÁRIA NO MUNDO PÓS-COLONIAL
}

\author{
"SECOND CLASS CITIZEN": FEMALE SUBJECTS AND IDENTITY FRAGMENTATION \\ IN A POST-COLONIAL WORLD
}

Maria Isabel Lemos ${ }^{1}$

ORCID: https://orcid.org/0000-0003-3881-4977

\begin{abstract}
Resumo: A contemporaneidade, marcada por constantes deslocamentos geográficos, simbólicos e ontológicos, carrega as marcas de seu tempo; e também os traços históricos da exploração colonial e da fragmentação identitária que a mesma potencializou. Esta análise literária, baseada no volume "Cidadã de Segunda Classe" (2018), da nigeriana radicada em Londres Buchi Emecheta, visa à problematização da experiência de fragmentação e transmutação identitária vivenciada por migrantes, bem como seus efeitos contemporâneos. Nesta reflexão, o papel da Literatura como ferramenta para a consolidação do locus enunciativo de tais grupos e sujeitos é abordado, assim como a sua centralidade para a reconstrução de narrativas históricas e políticas com base no processo dialético de estruturação das identidades. A partir das experiências da personagem Adah, de caráter altamente autobiográfico, observam-se diferentes tipos de deslocamento e alteridade: o lugar da mulher na sociedade patriarcal igbo, o enquadramento das imigrantes africanas, e de seus descentes; na estrutura social inglesa e a importância das mesmas para o estabelecimento de novos sujeitos femininos e perspectivas literárias. O volume, publicado na década de setenta do século XX, levanta inúmeras questões que se refletem na atualidade e contribuem para a compreensão dos processos históricos de desterritorialização e ressignificação identitária aqui abordados.
\end{abstract}

Palavras-chave: Buchi Emecheta; colonialismo; fragmentação identitária; análise literária

\begin{abstract}
Contemporaneity bears the marks of its time such as geographical, symbolic and ontological shifts, but also the historical traces of colonial exploitation and the identity fragmentation that it potentiated. This literary analysis, based on the volume "Second Class Citizen" (2018) by the Nigerian writer Buchi Emecheta, aims to problematize the identity fragmentation and transmutation experienced by immigrants, as well as its contemporary effects. In this reflection, the role of Literature as a tool for the consolidation of a new enunciative locus of such groups and subjects is addressed, as well as its centrality for the reconstruction of historical and political narratives based
\end{abstract}

\footnotetext{
${ }^{1}$ Maria Isabel Lemos é antropóloga e focaliza sua investigação em Práticas e Políticas da Cultura no âmbito das Tradições Orais, do Património Cultural Imaterial, da Performance e da Literatura. É doutoranda integrada nos centros de acolhimento e investigação Centro e Rede de Investigação em Antropologia (CRIA) e no Instituto de Estudos de Literatura e Tradição (IELT), e integra o projeto "The Literary Encyclopedia". Cursa o programa doutoral Antropologia: Políticas e Imagens da Cultura e Museologia (ISCTE-IUL). Desenvolveu um projeto de investigação doutoral em Cabo Verde e outros em parceria com o Instituto do Património Cultural local. Integra o grupo de investigação "Narrative Cultures" do SIEF. Mestre em Culturas Visuais pela Faculdade de Ciências Sociais e Humanas da Universidade NOVA de Lisboa (FCSH-UNL) e Bacharel em Relações Internacionais, trabalhou para o Programa das Nações Unidas para o Meio Ambiente (PNUMA/UNEP) no Brasil e com diferentes iniciativas culturais em Portugal. mariaisabelm.lemos@ gmail.com
} 
on the dialectic process of identity construction. Based on the highly autobiographical experiences of the character Adah different types of displacement and alterity can be observed: the place of women in Igbo patriarchal society, the framing of African immigrants, and their descendants, in the English social structure, and the importance of immigrant women to the establishment of new literary perspectives and female subjects. The volume, published in the 70's, raises questions that reflect in today's society and contributes to the understanding of the historical processes of deterritorialization and identity re-signification here addressed.

Keywords: Buchi Emecheta; colonialism; identity fragmentation; literary analysis

\section{Introdução}

A análise do legado literário de Florence Onyebuchi, comumente reconhecida como Buchi Emecheta, perpassa diversificadas temáticas como a expressão literária e o papel social de mulheres africanas (BRUNER; BRUNER, 1985); a maternidade (KATRAK, 1987), as complexidades do encontro colonial e da imigração (BARTHELEMY, 1989) e, principalmente, a desigualdade de gênero (SOUGOU, 2002). Os volumes publicados pela autora, nascida em Lagos e radicada em Londres, constituem um pilar central na afirmação de sujeitos, perspectivas e experiências literárias dos grupos colonizados e na produção literária de autores da diáspora nigeriana, que passam a exercer o domínio sobre suas narrativas a partir das décadas de sessenta e setenta do século passado (HARRIS, 1975, p. 433) e a questionar a lacuna histórica de sua representatividade.

O volume aqui observado, "Cidadã de Segunda Classe", publicado pela primeira vez em 1974, foi, no decorrer do tempo, particularmente analisado por seu conteúdo sócio cultural e pelo teor autobiográfico dos fatos narrados a partir das experiências da personagem Adah Obi, profundamente semelhantes às de Emecheta. No livro, conjuntamente com "No Fundo do Poço" (2019) e "Head Above Water" (1986), sendo o último uma autobiografia, a autora explora problemáticas centrais ao conflito intercultural e à experiência de deslocamento da imigração no mundo pós-colonial como, por exemplo, o racismo, a estereotipação, a desigualdade social e a hibridização identitária (BRUNER; BRUNER, 1985, p. 9). Anthony Barthelemy (1989, p. 559) caracteriza a complexidade desse deslocamento e a multiplicidade do processo identitário:

Torn between loyalties of race, culture, and sex, Emecheta writes about a world lost and a world becoming, a world destroyed and a world 
indestructible. The Africa of Emecheta's novels is a continent reeling in two times: Western diachronicity and traditional African synchronicity.

A experiência transcultural de Adah Obi retrata, justamente, a fragmentação sugerida na passagem anterior: a partir da caracterização patriarcal da sociedade $i g b o^{2}$; e do consequente desajustamento da personagem à tal estruturação social, e da desconstrução de uma Inglaterra idílica, é construída uma narrativa cujo sustentáculo reside no deslocamento, nas experiências decorrentes do mesmo e na constante reconstrução identitária da personagem que se depara com a alteridade, a dificuldade de pertença e partilha das tradições comunitárias na Nigéria, o desenquadramento na sociedade inglesa e as complexidades dialéticas dos múltiplos processos identitários que vivencia a partir das fragmentadas categorizações sociais de gênero, raça, etnia, classe social e profissional em um contexto pós-colonial.

Os desdobramentos da exploração econômica, cultural e política do colonialismo podem ser observados nas relações transnacionais contemporâneas e na construção de subjetividades múltiplas que encontram na Literatura, por exemplo, uma forma de expressão de sua multiculturalidade e um veículo para suas perspectivas e experiências de pertencimento relativas ao país de origem - ou, atualmente, de origem das gerações anteriores - e ao país que habitam. A "literatura diaspórica" é um exemplo frutífero do redimensionamento de subjetividades e narrativas construídas no pós-colonialismo e sintetiza as obras que retratam, justamente, a negociação subjetiva e política decorrente dos deslocamentos entre fronteiras territoriais e simbólicas, além de desconstruir o cânone das literaturas nacionais.

A análise aqui desenvolvida objetiva a problematização das relações contemporâneas entre a produção de escritores que baseiam suas obras em experiências de deslocamento associadas ao colonialismo e o estabelecimento de novos sujeitos e narrativas literárias e históricas. Para tal, fundamenta-se em conceituações da identidade enquanto processo

\footnotetext{
${ }^{2}$ Dispersos pelo centro sul e sudeste da Nigéria, o povo igbo representa uma grande parcela da população nigeriana e, ao longo do tempo, foi alvo de inúmeras investigações dedicadas à análise e ao registro de sua cultura e história, bem como de suas adaptações. A título de contextualização, as palavras do historiador nigeriano Don C. Ohadike, um dos maiores conhecedores da temática, na "Introdução" ao volume "Things Fall Apart" (1996, p. xix), de Chinua Achebe:

The Igbo (or Ibo) people form one of the largest ethnic groups in Africa (...). The Igbo language has dozens of dialects, which developed because Igboland was an aggregation of self-contained towns and villages, separated from each other by dense bush. Before the twentieth century it would have been incorrect to speak of the Igbo as a single people; they were made up of over two hundred separate groups. (...) However, during the colonial period (1900-1960) many Igbo people ventured far from home and congregated in urban centers, at work place, and in institutions of higher learning.
} 
situacional e dialético, que não se resume à dimensão local ou territorial de caracterização dos sujeitos (WOODWARD, 1997). Não são desconsiderados, nesta análise, os inúmeros prismas a partir dos quais o conceito foi analisado e as muitas revisões a que é constantemente submetido dada a natureza dinâmica, como argumentado por Zygmunt Bauman (1998, 2001), de adaptação da identidade de acordo com as transformações estruturais locais e globais. A revisão histórica do conceito, entretanto, ultrapassa os limites propostos nesta análise. A identidade será aqui compreendida de forma dinâmica (RUTHERFORD, 1990) e enquanto prática discursiva e construção narrativa que emerge de encontros situacionais - posicionamento que ecoa as propostas de Homi Bhaba (1992) e Néstor Canclini (1995) - e encontra-se, por isso, em constante reconstrução e sujeita a relações de poder.

As dimensões simbólica e social da construção identitária ou da identificação, como proposto por Stuart Hall (2000), consequências de sua situacionalidade e dialética, desvinculam o conceito da noção de território e de vínculo geográfico como fundamentais à sua caracterização. Nesse sentido, a proposta de Édouard Glissant em "A Poética da Relação" $(2011)^{3}$ de observação da identidade enquanto fato rizomático, ou seja, aquele em que o enraizamento totalitário é substituído pelo prolongamento através das relações com o outro, também figura como um importante enquadramento de análise. Paul Gilroy, em " $\mathrm{O}$ Atlântico negro: modernidade e dupla consciência" (2012), também se apoia na constituição rizomática para sustentar o conceito de "dupla consciência" dos sujeitos na diáspora, ou seja, a concomitante pertença e não-pertença ao Ocidente. Por fim, da observação dos deslocamentos simbólicos e ontológicos - além do territorial -, emerge o caráter fragmentado das identidades na contemporaneidade e seu impacto político e de agencialidade na construção de fronteiras simbólicas (HALL, 2000, p. 7).

Para além da complexa definição de identidade, será aqui fundamental a conexão do conceito com a temática da migração e suas especificidades. De acordo com Hashmi (2000, p. 164):

immigrant identity is a particular one since it involves the reevaluation of oneself and one's identity when being situated in a strange environment and surrounded by different customs, traditions, and language to which the immigrant is expected to adjust.

\footnotetext{
${ }^{3}$ Ressalta-se que o autor baseou suas propostas no conceito de "rizoma", de Gilles Deleuze e Félix Guattari. O rizoma deleuze-guattariano foi apresentado no volume "Rhizome" (1976).
} 
Ademais da reconsideração do sujeito, a migração envolve diferentes variantes e constitui diversas experiências de acordo com os impulsos que a motivam e os contextos de deslocamento dos indivíduos. Debates específicos relativos às tendências globais de migração e estudos de caso locais problematizam padrões que englobam categorias como gênero e faixa etária, bem como fatores geográficos e históricos que impulsionam tais deslocamentos.

Dentre tais fatores históricos, o colonialismo e suas reproduções na contemporaneidade, quando consideradas suas dimensões política, econômica e ideológica, figuram como importantes alavancas dos processos migratórios do século XX. No caso dos fluxos entre Reino Unido e Nigéria, assim como do deslocamento rural-urbano nigeriano, o histórico de exploração colonial teve forte impacto na desestabilização econômica, política e de modelo produtivo, predominantemente rural. A falta de recursos - apesar da centralidade do país para o mercado petrolífero - figura como uma das principais motivações para a migração de nigerianos cuja vasta e complexa diáspora confirma a tendência ao deslocamento. Sobre o tema, o artigo "Evolution of Nigerian Diaspora in Britain: Issues, Perspectives, and a Continuing Debate" (2016), de Abiodun Adeniyi, figura como um exemplar estudo de caso, centralizado na experiência diaspórica de nigerianos frente à comum generalização da "diáspora africana".

As especificidades do legado literário de Emecheta no que se refere à Literatura enquanto ato político e de significação, capaz de refletir os deslocamentos característicos à contemporaneidade, serão problematizadas à luz de propostas que desconstroem o caráter nacionalista da Literatura e assumem a problemática identitária como central para a mesma. Segundo Zilá Bernd (2007, p.1), urge discutir

o desgaste do conceito de "literatura nacional" e aprofundar a questão dos diferentes tipos de mobilidade cultural e a necessidade de flexibilizar terminologias como as de identidade e literatura nacionais que responderam, nos séculos XIX e XX a uma necessidade de definir pertencimentos, mas que se revelam insuficientes na virada do século XXI.

Observar a conexão entre produção literária e identidade, essencialmente política, implica desconstrução da pertença única, ou, como proposto, aceitação do caráter rizomático da construção identitária. As experiências de deslocamento e as narrativas delas emergentes, bem como as práticas discursivas desses autores e de seus sujeitos literários, representam um exercício político de representatividade e de revisão do passado a partir de suas 
perspectivas. Determinadas obras, como "Cidadã de Segunda Classe", contribuem para a compreensão das experiências e da pertença dos grupos deslocados, mas também para a caracterização de suas sociedades e culturas de origem a partir da forma como as mesmas são retratadas. Tal especificidade representa uma suspensão da barreira geográfica e temporal: a recriação dos percursos de deslocamento traduz perspectivas sobre diferentes localidades e temporalidades; e sobre a forma como as mesmas impactam a construção identitária dos indivíduos.

A análise, portanto, apesar de se dedicar a um volume publicado na década de setenta, considera sua centralidade para uma série de questionamentos que o perpassam literária e politicamente e que se refletem na contemporaneidade: as experiências de Adah Obi traduzem, em sua medida, as vivências de Buchi Emecheta e revelam o estabelecimento de novas perspectivas literárias, assim como a inauguração de novos espaços de expressão e publicação para mulheres negras e imigrantes. Assim como Emecheta, autoras como Chimamanda Ngozi Adichie, Scholastique Mukasonga, Yaa Gyasi e Djamila Pereira de Almeida são exemplos diversificados do poder que a quebra de tais barreiras traz para a pluralização da Literatura e, também, para o preenchimento de lacunas discursivas relativas ao presente e ao passado, e para novas articulações do último. Apesar da diferença geracional e, portanto, de experiências e subjetividades que separam sua produção, tais autoras exploram a conexão entre os textos literários e sua dimensão histórica e sociocultural ao apresentarem conjuntos de representações que refletem a fragmentação identitária decorrente de deslocamentos geográficos e simbólicos. Sobre o legado de Buchi Emecheta, Sougou considera que a escritora (2002, p.31), "taking the power of the word into her own hands, represents and projects a presence, an identity, that is neither purely individualistic nor purely collective; it 'merges the shared and the unique,". A união entre o individual e o coletivo, neste caso, associa-se à dimensão histórica: a partir de tais obras, pluralizam-se vozes, experiências, memórias, passados e presentes centrais à nossa compreensão do mosaico a que denominamos contemporaneidade.

\section{Adah, a sociedade igbo e o mito da metrópole idílica}

“Cidadã de segunda classe" estrutura-se de forma cronológica e em concordância com as vivências de sua personagem principal, Adah. Os primeiros capítulos dedicam-se a suas memórias e traumas de infância, descrições das impressões da menina acerca do 
universo que a circunda e dos contratempos que estorvam seus principais planos: ter acesso aos estudos e ir para o Reino Unido. O embate de Adah com determinadas regras que gerem a estrutura social igbo em que vive, principalmente as relacionadas às questões de gênero e ao papel social da mulher, é clarificado desde o princípio por meio de episódios em que a personagem desafia as convenções sociais para atingir objetivos como ir à escola - atividade que os igbo consideravam importante mas que, dependendo das condições familiares, era privilégio dos rapazes - e escolher um marido que a agradasse minimamente (EMECHETA, 2018, p. 13).

O começo da narrativa, que se desenvolve na década de sessenta e tem início em Lagos, dedica-se à caracterização do universo experienciado por Emecheta e, consequentemente, por Adah, com base no embate entre as várias culturas coexistentes na Nigéria, a presença inglesa e estadunidense no país recém-independente e a visão da personagem sobre o encontro entre tais grupos. No caso de Adah, o sonho de migrar para o Reino Unido encontra-se associado às várias experiências da personagem enquanto mulher dentro de sua estrutura social e, principalmente, à sua vontade de concluir os estudos e evoluir profissionalmente - desejo que a personagem denomina, ao longo do livro, de "A Presença". A indicação do embate entre Adah e a sociedade igbo figura em diversas alturas de sua trajetória:

Uma menina havia chegado quando todos esperavam e previam um menino. Assim, já que era um desapontamento tão grande para os pais, para a família imediata, para a tribo, ninguém pensou em registrar seu nascimento. (Ibid., p.11)

Nunca, nunca na vida se casaria com homem nenhum, rico ou pobre, a quem tivesse de servir as refeições de joelho dobrado: não admitiria viver com um marido a quem tivesse de tratar como ano e chamar de "senhor" mesmo quando ele não estivesse ouvindo. Sabia que todas as mulheres igbo faziam isso, mas nunca agiria assim! (Ibid., p.29)

Adah se viu sozinha, forçada a enfrentar uma situação ditada pela sociedade na qual, enquanto indivíduo, dispunha de poucas opções. (Ibid., p. 41)

As dificuldades mencionadas na transcrição relacionam-se aos esforços de Adah após a morte inesperada de $\mathrm{Pa}$ - seu pai - a que se seguiu o novo e infeliz casamento de Ma, sua mãe, e a passagem de sua guarda para o tio, para quem Adah passa a trabalhar como doméstica. A ameaça de ter de deixar os estudos por conta da falta de meios e da necessidade de dar continuação à educação de seu irmão, Boy, são compensadas pelo esforço, aplicação 
e autodeterminação de Adah, que prefere castigos à possibilidade de deixar a escola. $\mathrm{O}$ último de tais castigos - que só descobrirá como tal após a mudança para a Inglaterra resume-se a seu casamento com Francis que, para a jovem, constituiu uma oportunidade de continuar a estudar e ter uma família que a representasse pois, em "Lagos, na época, os adolescentes não podiam morar sozinhos e se, por acaso, para completar, esse adolescente fosse uma menina, viver sozinha significava ir atrás de encrenca. Em suma, Adah teria de casar" (Ibid., p. 35).

O embate entre as aspirações individuais, a construção identitária e o desenvolvimento de Adah e o modelo social que a circundava, ou que corresponde a suas lembranças, é a primeira problemática identitária que emerge na narrativa. Inclusivamente, a construção das personagens masculinas e sua representação frente à identidade e o gênero de Adah serve, ao longo do volume, à exploração desse embate e à exposição do sexismo vivenciado pelas mulheres no âmbito dos papeis tradicionais de gênero da sociedade igbo e da Nigéria - à altura. Francis, o maior antagonista de Adah, principalmente após a mudança para a Inglaterra, personifica toda a estrutura sexista em questão e, além de antagonista em termos literários, representa o "outro" na dialética de identificação caracterizada pelo gênero. As expectativas da sociedade para Adah (ser uma esposa obediente e boa mãe) diferiam radicalmente de seus propósitos, apesar de a personagem se provar excelente na maternidade ao longo do volume e da obra "No Fundo do Poço", relativa à vida de Adah após a separação de Francis.

Dessa profunda fissura identitária e dos traumas que a mesma implica, em associação ao mito da metrópole idílica, civilizada e cheia de oportunidades, emerge o sonho de Adah em emigrar para o Reino Unido. Em suas memórias de infância, pululam episódios que sustentam a visão coletiva errônea do país colonizador e, ao mesmo tempo, demonstram como, no pós-independência, inúmeras das lógicas exploratórias e ocidentais foram replicadas. Ilustrativas, algumas passagens corroboram o argumento:

O nome "Reino Unido", quando pronunciado pelo pai de Adah, tinha um som tão pesado... o tipo de ruído que se associa a bombas. (...) Sem dúvida, ir ao Reino Unido era como fazer uma visita a Deus. Ou seja, o Reino Unido devia ser uma espécie de Paraíso. (Ibid., p.12)

Mas fez uma promessa secreta para si mesma: um dia iria ao Reino Unido. Sua chegada ao Reino Unido seria o pináculo de suas ambições. Não ousava contar a ninguém; podiam concluir que era preciso mandar examinar a cabeça dela, ou algo do tipo. Uma garotinha como ela, com um 
pai que não passava de empregado na ferrovia e uma mãe que não sabia coisa alguma além da Bíblia igbo e do hinário igbo-anglicano, da Introdução até o Sumário, e que ainda acreditava que Jerusalém se localizava junto à mão direita de Deus! (Ibid., p.23)

O Reino Unido emerge na narrativa pessoal de Adah (e de Emecheta) com dupla função: a de "pináculo das ambições" e de derradeira tentativa de escape dos entraves sociais. Salienta-se que a personagem, após casar com Francis, ter a primeira filha e terminar seus estudos de biblioteconomia, começa a trabalhar na Biblioteca do Consulado Americano, transformando-se na provedora da família, papel que desempenha durante todo o casamento e após o divórcio. Adah propõe a Francis que termine seus estudos na Inglaterra com o intuito de realizar, com o marido, a mudança. Novamente, as práticas e estruturas sociais emergem como entrave: Francis pede permissão a seu pai, que sugere que apenas o marido embarque na viagem enquanto Adah continua a trabalhar e sustentar seu núcleo familiar e os parentes do marido, bem como seus estudos. Novamente, a autodeterminação da personagem faz com que aceite o modelo proposto com o intuito de convencer sorrateiramente os sogros e o marido de que sua ida - com os filhos - trará mais prestígio e meios à família.

A expectativa de uma vida melhor depositada no deslocamento para o Reino Unido, que encontra eco na migração de mulheres nigerianas até hoje, após as dificuldades e sucessos de Adah em contornar o tradicionalismo de sua sociedade e construir uma identidade a que se adequasse, é rapidamente desconstruída:

Você deve saber, querida jovem lady, que em Lagos você pode ser um milhão de vezes agente de publicidade para os americanos; pode estar ganhando um milhão de libras por dia; pode ter centenas de empregadas; pode estar vivendo como uma pessoa da elite, mas no dia em que você chega à Inglaterra vira cidadã de segunda classe. (Ibid., p. 58)

A teoria de que da migração decorreria um amadurecimento civilizacional - ideal fortemente marcado pela lógica colonial e pela educação católica e ocidentalizada de Adah nas instituições escolares - também desmorona nas primeiras interações do casal após o tempo em que Francis residiu sozinho no país:

Adah se calou ao ouvir a irritação na voz de Francis. Uma irritação que parecia proclamar: "Os machos africanos têm o direito de vir para a 
Inglaterra para ficar civilizados, só que esse privilégio ainda não foi concedido às fêmeas. (Ibid., p. 55)

Desmoronam, no deslocamento para Londres, o universo amoroso de Adah que, "desde o dia do casamento civil dos dois, vira o lado romântico de sua vida se estilhaçar ao redor, como um vidro que se parte" (Ibid., p. 40-41), e seus padrões de auto referência como mulher de sucesso e integrante da elite nigeriana. Tais desconstruções contribuem fortemente para a fragmentação identitária da personagem e para o desenvolvimento de novas identificações que emergem das situações a que a mesma é exposta. Ao descobrir o tipo de acomodações e trabalhos a que eram sujeitos os negros imigrantes e a que, até hoje em inúmeras partes do mundo, continuam a sê-lo, a autora ilustra a fragmentação referencial:

Então, para seu horror, Adah se deu conta de que teria que dividir a moradia com nigerianos do tipo dos que na Nigéria a chamavam de madame; alguns deles tinham o mesmo nível, em matéria de instrução, de suas criadas pagas. Sabia que tivera uma infância terrível, mas, mesmo assim, na Nigéria, as distinções de classe estavam começando a ser estabelecidas. (Ibid., p.57)

A dupla marginalização a que é exposta na Inglaterra transforma-se em uma reflexão constante na narrativa e caracteriza-se pela descrição das condições de vida, trabalho e alojamento em que passa a se enquadrar por conta de sua origem, etnia e da racialização, assim como nas memórias dos abusos sofridos no âmbito doméstico por conta da mentalidade sexista de Francis. Assim, duas outras problemáticas identitárias emergem: Adah, que anteriormente se preocupava mais objetivamente com as limitações impostas às mulheres, passa a experienciar cotidianamente o racismo estrutural e a opressão da estrutura desigual de classes. O deslocamento, antes geográfico, ganha dimensões simbólicas para a personagem que, apesar de encontrar trabalhos em bibliotecas em Londres, lugar raramente ocupado por mulheres imigrantes e negras, lida com embates identitários relativos às suas experiências sociais na Nigéria e no Reino Unido.

\section{Etnia, gênero e racialização: confrontos e deslocamentos}


A síntese desta análise - a relação entre construção identitária, deslocamento, Literatura e o estabelecimento de novos sujeitos e narrativas literárias - é indissociável de debates e movimentos sociais acerca de temáticas como pertença étnica, desigualdade de gênero, racismo estrutural e racialização. Duplamente marginalizada por ser mulher e negra, Adah experiencia, ainda, os confrontos com nigerianos de outras etnias que não a igbo e o estranhamento por parte das demais famílias e vizinhos provenientes do continente africano por sua conduta incomum: a jovem mãe recusa-se a entregar os filhos para adoção, prática estabelecida entre pais africanos e estudantes que migravam para a Inglaterra. Sobre as motivações, Emecheta clarifica (Ibid., p. 70): "Só cidadãos de primeira classe viviam com os filhos, não os negros". Para além das condições de habitação, trabalho e do preconceito, a adoção permitia às mães recém-libertas da intromissão familiar que estrutura a convivência social na Nigéria, principalmente no caso das mulheres, a construção das suas próprias identidades e experiências enquanto indivíduos para além da esfera doméstica e do papel de esposa. Sobre o procedimento, a maior denúncia ao caráter estrutural da racialização figura na escolha sistemática das mães adotivas:

Ninguém se preocupava em saber se a mãe era ou não adequada, ninguém queria saber se sua casa era limpa ou não; a única preocupação de todas era que a mãe adotiva fosse branca. O conceito de "brancura" acobertava um sem-número de pecados.

(Ibid., p. 68)

Sobre a dissimulação de pecados sob o véu da "brancura", é central a problematização de que o debate ultrapassa a esfera meramente identitária, como propõe a filósofa Djamila Ribeiro em “Quem tem medo do feminismo negro?” (2020). Levando-se em consideração a distância temporal entre esta reflexão e a publicação do volume, apesar do aumento de movimentos e lutas sociais antirracistas, a racialização e o racismo estrutural continuam a ser práticas reproduzidas e que estão diretamente ligadas, assim como as migrações do século XX, à exploração colonial, à escravidão e à consequente diáspora dos povos do continente africano. A branquitude, enquanto lugar de privilégios simbólicos e práticos, revela a necessidade de pensarmos "como algumas identidades são aviltadas" (RIBEIRO, 2020, p.27) e, ainda, a imprescindibilidade de leitura de "autoras negras, respeitando suas produções de conhecimento e se permitindo pensar o mundo por outras lentes e geografias da razão. É um convite para um mundo no qual diferenças não signifiquem desigualdades" (Ibid., p.27). As obras de Buchi Emecheta despontam como um 
importante exemplo desse tipo de produções e o volume aqui analisado permite, para além da pluralização de perspectivas, compreender processos sociais e identitários a partir dos sujeitos comumente marginalizados, ou seja, potencializa a construção de novos passados, presentes e futuros.

Enquanto o deslocamento de Adah - e das demais mulheres nigerianas - pode ter representado maior liberdade relativamente à família, ao matrimônio e ao trabalho, sua identificação com as mulheres inglesas brancas permaneceu marcada pela hierarquização e pela alteridade. As colegas de trabalho de Adah faziam-na se sentir inferior, apesar da mesma idade, assim como sua experiência negativa com uma babysitter integrada ao aparato estatal denuncia o privilégio e o "acobertamento de pecados" previamente referidos. Se, na Nigéria, Adah pertencia a uma classe social superior, o deslocamento para a Inglaterra a posiciona em um confronto de alteridades cujos marcadores de gênero e etnia, problemáticas centrais desde sua infância, passam a estar acompanhados pela racialização.

A produção de Buchi Emecheta é um marco, para além da alta qualidade literária, pela diversificação de sujeitos femininos. Sobre a luta feminista, entretanto, é importante referir que a autora identificou-se, ao longo de sua vida e de diversas entrevistas, com a teoria social conhecida por "Womanism", termo cunhado pela escritora Alice Walker (1983) e que, apesar da complexa definição que a mesma apresenta, trata de problematizar um feminismo que englobe a perspectiva da mulher negra e reconheça a marginalização múltipla que esta vivencia (racial, de gênero e classe). Relativamente à diversificação de sujeitos e à caracterização de personagens femininas, as obras de Emecheta sustentam as importantes críticas literárias de caráter feminista acerca da representatividade das mulheres e, também, de sua inserção no mercado editorial. Entretanto, Adah, que desenvolve ao longo do texto o desejo de ser escritora, representa, para a época, uma tripla quebra de padrão: a voz da mulher, negra e imigrante. Assim, na batalha contra estruturas sociais sexistas, a identidade feminina é plural e funde-se a outras lutas identitárias emergentes de outros conflitos de alteridade.

A dificuldade da mulher negra em encaixar-se nessas bandeiras é expressa de forma clara pelo próprio desenvolvimento do volume e pelo posicionamento de Adah frente às sociedades igbo e inglesa. A reivindicação desta representatividade, desenvolvida em termos teóricos e literários por inúmeras autoras, perpassa justamente a publicação de obras como as de Buchi Emecheta, em que a narrativa do deslocamento é contada por quem o vive. 


\section{Sra. Obi; Adah ou Buchi?}

A autodeterminação de Adah pode ser apontada como fator determinante para a construção identitária ao longo do volume e na qual se, por um lado, certos traços socioculturais ingleses são apropriados pela personagem, sua relação reflexiva com as culturas igbo e da Nigéria; bem como seu papel de combate às desigualdades de gênero, à estereotipação e à racialização emergem como fortes posicionamentos. No decurso desta edificação, pode ser observada a relação aqui explorada entre agencialidade política, Literatura e pluralização de sujeitos: Buchi Emecheta, ao construir um volume de teor autobiográfico estabelece um locus enunciativo que, com base em suas experiências, memórias e perspectivas, atenta para as diversas fases do processo migratório em que o deslocamento territorial é, muitas vezes, precedido por outros tipos de deslocamentos, como a inadequação da personagem à estrutura sexista do universo simbólico igbo.

Além de tal detalhamento, a autora esmiúça a sequência de episódios que contribuem para a identificação da mesma com diferentes atributos de ambas as culturas (COX, 2010). Novos marcadores identitários emergem durante a trajetória, a partir das dialéticas que vivencia, e a Literatura consolida a distância da autora do que Zygmunt Bauman (2005, p.46) determina como "identidade da subclasse", ou seja, a inexistência de pertencimento por parte de indivíduos socialmente marginalizados. A partir da crise de pertencimento, como proposto pelo mesmo autor (op. cit.), Buchi constrói uma identidade e é capaz de narrá-la por meio das experiências de Adah e, de forma mais abrangente, da Literatura. Segundo Canclini (1995, p. 124) "a identidade surge, na atual concepção das ciências sociais, não como uma essência intemporal que se manifesta, mas como uma construção imaginária que se narra": levando-se em consideração a dimensão narrativa da identidade e sua importância para a representatividade dos indivíduos, o locus enunciativo de Emecheta legitima as experiências e perspectivas de determinados grupos e estabelece um fio conectivo entre fatos históricos e processos contemporâneos.

Ao fim da obra, após o divórcio conturbado de Francis, que se revela uma personagem violenta, abusiva e cruel, Adah encontra em Londres um colega de escola que a chama por "Nne nna", apelido de infância. O retorno momentâneo àquela fase de sua vida é apresentado como uma "intervenção da Providência" para que Adah prosseguisse em seu caminho de liberdade, ainda que possuísse "nada além de quatro bebês, um emprego novo e uma caixa de trapos" (EMECHETA, op. cit., p. 246). A simbologia da digressão fala sobre 
autodeterminação e também sobre a escolha da personagem em construir a si própria com o melhor que ambas as sociedades lhe puderam oferecer, além de explicitar a multiplicidade de construções e desconstruções de autoreferência experienciadas ao longo do processo de deslocamento e amadurecimento e que carregará para sempre consigo. Nne nna, Adah, Sra. Obi, novamente Adah, Buchi Emecheta. Todas fazem parte de um complexo processo em que a multiplicidade de tempo e espaço materializa-se nas identificações construídas pelos indivíduos em função de suas experiências socioculturais.

O episódio de violência que representa o estopim e o divórico para Adah é igualmente simbólico: Francis queima o manuscrito do primeiro livro escrito pela então Sra. Obi, que o considera como um filho. A passagem "Francis estava queimando sua história; já queimara toda ela. A história na qual estava apoiando seu sonho de se tornar uma escritora" (Ibid., p. 245) revela ainda a construção identitária da personagem enquanto escritora e os embates que teria de enfrentar para performar tal identidade, principalmente quando consideradas a racialização, as desigualdades de gênero e social e a marginalização dos imigrantes, todos obstáculos com os quais se confrontou ao longo de sua vida.

\section{Conclusão}

A problematização da experiência de fragmentação e transmutação identitária vivenciada por imigrantes, bem como seus efeitos contemporâneos, foi, nesta reflexão, analisada com base no papel da Literatura como ferramenta para a consolidação do locus enunciativo de tais grupos e sujeitos, assim como para a reconstrução de narrativas históricas e políticas com base no processo dialético de construção das identidades. A obra "Cidadã de Segunda Classe", apesar de enquadrar a emergência de subjetividades que refletem o contexto social da década de setenta, diverso do contemporâneo, retrata o processo de construção de identidades transnacionais e multiculturais que, na atualidade, se complexificam. Nesse sentido, a escolha do volume para análise fundamentou-se em sua qualidade literária, mas também em sua importância fundamental para o estabelecimento de uma subjetividade específica (a mulher negra, imigrante e escritora) e de uma corrente literária cada vez mais expressiva, principalmente quando se pensa na produção de escritoras nigerianas - ou descendentes de nigerianos - na diáspora e o peso político de suas obras (OKEREKE, 1997). 
Consideradas as temáticas extremamente atuais e estruturais como a xenofobia, o racismo, a desigualdade de gênero e social, e o contexto contemporâneo de ascensão, em diversas partes do mundo, de governos de extrema-direita com tendências totalitárias, a reflexão acerca dos processos que fundamentam a produção de novas subjetividades e a compreensão dos mecanismos históricos que os potencializaram como, por exemplo, o colonialismo, é central para a construção de sociedades em que a alteridade não pressuponha desigualdade. O estabelecimento de novos sujeitos femininos e a pluralização de vozes representados por essa obra reforçam o papel primordial da Literatura na construção da representatividade e nas lutas sociais e políticas. A excepcionalidade da obra de Emecheta, em sua totalidade, reside, justamente, na instrumentalização da Literatura em função da tradução dos processos de hibridização identitária e da formação subjetiva de sujeitos marginalizados. Consequentemente, os volumes têm potencial representativo e político, atingindo concomitantemente o quadro social nigeariano e o britânico, desconstruindo estereótipos presentes e passados, pluralizando versões da História e explicitando a complexidade por trás da formação de identidades transnacionais. O teor autobiográfico do livro, neste caso, contribui largamente para seu peso sociopolítico e, ao passo que denuncia e caracteriza a marginalização na Inglaterra, também se ocupa-da denúncia de determinadas práticas igbo, construindo um retrato dessa cultura.

Por fim, "Cidadã de Segunda Classe" é uma obra que reflete o deslocamento geográfico e sua dimensão imaterial: os confrontos simbólicos vivenciados por Adah vinculam-se à construção e à desconstrução de fronteiras e identidades cuja demarcação emerge da socialização presente e das marcas do passado, ou seja, "dos discursos da cultura e da história" (HALL, op. cit, p. 70). A condição rizomática da experiência identitária de Adah está circunscrita à sua batalha pela afirmação de subjetividades que, a priori, não lhe pertenceriam: a personagem não se enquadra na condição feminina na Nigéria, assim como não assume o ethos de "cidadã de segunda classe", apesar de vivenciá-lo, como um fato dado. Nesse sentido, para além da autodeterminação, Emecheta retrata a grande necessidade de posicionamento contestatório sobre as estruturas e práticas discursivas hegemônicas que marginalizam determinadas identidades e mascaram o presente a partir de narrativas dominantes do passado. Ao iluminar sua experiência de deslocamento, contribui para a compreensão de complexas temáticas, centrais à contemporaneidade, como o pertencimento, a identidade e a alteridade. 


\section{Referências}

ADENIYI, A. Evolution of Nigerian Diaspora in Britain: Issues, Perspectives, and a Continuing Debate. Historical Research Letter, International Knowledge Sharing Platform (IISTE), $\quad$ v. $\quad 31, \quad$ p. $\quad 1-10, \quad 2016 . \quad$ Disponível em: https://www.iiste.org/Journals/index.php/HRL/article/view/29922/30734. Acesso em: 13 Abril 2021.

BARTHELEMY, A. Western Time, African Lives: Time in The Novels of Buchi Emecheta. Callaloo, Baltimore, n. 40, p. 559-574, 1989.

BAUMAN, Z. O Mal-estar da Pós-Modernidade. Tradução de Mauro Gama e Claudia Martinelli Gama. Rio de Janeiro: Jorge Zahar Ed., 1998. 276p.

Modernidade líquida. Tradução de Plínio Dentzien. Rio de Janeiro: Jorge Zahar, 2001. 280p.

Identidade: Entrevista a Benedetto Vecchi. Tradução de Carlos Alberto Medeiros. Rio de Janeiro: Jorge Zahar Ed., 2005. 119p.

BERND, Z. Colocando em xeque o conceito de literatura nacional. SIMPÓSIO INTERNACIONAL RELAÇÕES LITERÁRIAS INTERAMERICANAS SOBRE TERRITÓRIO E CULTURA, 1, Rio de Janeiro, 2007. Disponível em: https://www.zilabernd.com/arquivos/89/uff2007-pdf_145118.pdf. Acesso em: 27 Abril 2021.

BHABA, H. K. The World and the Home. Social Text, 31/32, Durham: Duke University Press, p. 141-153, 1992. Disponível em: https://www.jstor.org/stable/466222?seq=1. Acesso: 13 Abril 2021.

BRUNER, C.; BRUNER, D. Buchi Emecheta and Maryse Condé: Contemporary Writing from Africa and the Caribbean. World Literature Today, Oklahoma, v. 9, n. 51, p. 9-13, 1985. Disponível em: https://www.jstor.org/stable/40140523?seq=1. Acesso em: 26 Abril 2021.

CANCLINI, N. G. Consumidores e cidadãos: conflitos multiculturais da globalização. Rio de Janeiro: Ed. UFRJ, 1995. 268p.

COX, M. A. Buchi Emecheta: Re-imagining of the African Feminism Self. In: PANDURANG, M.; BARTELS, A. (Eds) African Women Novelists Re-Imagining Gender. Nova Déli: Pencraft International, 2010, p. 51-63. 
DELEUZE, G; GUATTARI, F. Rhizome: introduction. Paris: Editions de Minuit, 1976. $74 \mathrm{p}$.

EMECHETA, B. Head above water. Londres: Ogwugwu Afo, 1986. 243p.

Cidadã de segunda classe. Tradução de Heloisa Jahn. Porto Alegre: Dublinense, 2018. 256p.

No fundo do poço. Tradução de Julia Dantas. Porto Alegre: Dublinense, 2019. $192 p$.

GILROY, P. O Atlântico negro: modernidade e dupla consciência. Tradução de Cid Knipel Moreira. 2.ed. São Paulo: Editora 34, 2012. 468p.

GLISSANT, E. A Poética da Relação. Lisboa: Sextante Editora, 2011. 216p.

HALL, S. Quem precisa de identidade? In: SILVA, T. (Org.). Identidade e diferença: a perspectiva dos Estudos Culturais. Petrópolis: Vozes, 2000. p. 103-133.

HARRIS, H. Book Reviews: Second Class Citizen By BUCHI EMECHETA. Race \& Class, Londres, v. 16, n. 4, p. 433-435, 1975. Disponível em: https://journals.sagepub.com/doi/abs/10.1177/030639687501600411. Acesso em: 26 Abril 2021.

HASHMI, N. Immigrant Children in Europe: constructing a transnational identity. In: HOEFERT, A.; SALVATORE, A. (Eds) Between Europe and Islam - Shaping modernity, in a transcultural space. Bruxelas: Peter Lang, 2000. p. 163-173.

KATRAK, K. Womanhood/Motherhood: Variations on a Theme in Selected Novels of Buchi Emecheta.The Journal of Commonwealth Literature, Londres, v. 22, n. 1, p. 159$170,1987$.

OHADIKE, D. Igbo Culture and History. In: ACHEBE, C. Things Fall Apart, Londres, Heinemann, 1996, xix-xlix.

OKEREKE, G. Raising Women's Consciousness Towards Transformation in Nigeria: The Role of Literature. Issue: A Journal of Opinion, Cambridge, v. 25, n. 2, p. 28-30, 1997. Disponível em: https://www.jstor.org/stable/1166741?seq=1. Acesso em: 27 Abril 2021.

RIBEIRO, D. Quem tem medo do feminismo negro?. 11.ed. São Paulo: Companhia das Letras, 2020. 148p.

RUTHERFORD, J. Identity: Community, Culture, Difference. Dagenham: Lawrence \& Wishart, 1990. 239p.

SOUGOU, O. Writing Across Cultures: Gender Politics and Difference in the Fiction of Buchi Emecheta. Amsterdam: Editions Rodopi, 2002. 243p. 
M. I. Lemos

"Cidadã de segunda classe": sujeitos femininos e a

fragmentação identitária no mundo pós-colonial

WALKER, A. In Search of our Mothers' Gardens: Womanist Prose. California: Harcourt, 1983. 418p.

WOODWARD, K. Identity and difference. Londres: The Open University e SAGE Publications, 1997. 320p.

Artigo recebido em: 29.04.2021

Artigo aceito para publicar em: 19.07.2021 